Journal for ImmunoTherapy of Cancer

\section{Inability of granule polarization by NK cells defines tumor resistance and can be overcome by CAR or ADCC mediated targeting}

To cite: Eitler J, Wotschel N, Miller N, et al. Inability of granule polarization by NK cells defines tumor resistance and can be overcome by CAR or ADCC mediated targeting. Journal for ImmunoTherapy of Cancer 2021;9:e001334. doi:10.1136/ jitc-2020-001334

- Additional material is published online only. To view, please visit the journal online (http://dx.doi.org/10.1136/jitc2020-001334).

JE and NW contributed equally. Accepted 14 December 2020

Check for updates

(c) Author(s) (or their employer(s)) 2021. Re-use permitted under CC BY-NC. No commercial re-use. See rights and permissions. Published by BMJ.

For numbered affiliations see end of article.

Correspondence to Professor Torsten Tonn; t.tonn@blutspende.de

\section{ABSTRACT}

Background On encountering a susceptible target, natural killer (NK) cells mediate cytotoxicity through highly regulated steps of directed degranulation. Cytotoxic granules converge at the microtubule organizing center and are polarized toward the immunological synapse (IS), followed by granule exocytosis. NK cell retargeting by chimeric antigen receptors (CARs) or mAbs represents a promising strategy for overcoming tumor cell resistance. However, little is known about the lytic granule dynamics of such retargeted NK cells toward NK-cell-resistant tumors.

Methods Here, we used spinning disk confocal microscopy for live-cell imaging to analyze granulemediated NK cell cytotoxicity in ErbB2-targeted CARexpressing NK-92 cells (NK-92/5.28.z) and high-affinity FcR transgenic NK-92 cells plus Herceptin toward ErbB2positive breast cancer cells (MDA-MB-453), which are resistant to parental NK-92.

Results Unmodified NK-92 cells cocultured with resistant cancer cells showed stable conjugate formation and granule clustering, but failed to polarize granules to the IS. In contrast, retargeting by CAR or FcR+Herceptin toward the MDA-MB-453 cells enabled granule polarization to the IS, resulting in highly effective cytotoxicity. We found that in NK-92 the phosphoinositide 3-kinase pathway was activated after contact with resistant MDA-MB-453, while phospholipase C- $\gamma(\mathrm{PLC} \gamma)$ and mitogen-activated protein kinase (MEK)/extracellular signal-regulated kinase (ERK) were not activated. In contrast, retargeting by CAR or antibody-dependent cell-mediated cytotoxicity (ADCC) provided the missing PLC $\gamma$ and MEK/ERK signals.

Conclusions These observations suggest that NK cells can create conjugates with resistant cancer cells and respond by granule clustering, but the activation signals are insufficient to induce granule polarization and consequent release of Iytic enzymes. Retargeting by CAR and/or the FcR/mAb (ADCC) axis provide the necessary signals, leading to granule polarization and thereby overcoming tumor cell resistance. Keywords: NK cells, NK-92, haNK, ADCC, Chimeric Antigen Receptor (CAR), breast cancer, cancer immunotherapy, live-cell imaging, granule polarization

\section{BACKGROUND}

Natural killer (NK) cells are potent immune effector cells capable of recognizing and killing malignant or virus-infected cells. ${ }^{1}$ NK cell cytotoxicity is tightly regulated by a panel of germline-encoded natural cytotoxicity receptors, Fc receptors (FcR, CD16), adhesion molecules and inhibitory receptors (eg, killer-cell immunoglobulin-like receptors (KIRs)) and checkpoint molecules. Depending on the ligands expressed on tumor cells, the cumulative signals from activating and inhibitory receptors direct NK cells toward immune tolerance or immunological response. ${ }^{2}$ Cellular stress markers and target cell transformation stimulate activating NK cell receptors, while inhibitory ligands protect healthy self cells from eradication. NK cells can also be activated by IgG-opsonized malignant, virus-infected, or allogeneic cells through FcR signaling via antibody-dependent cell-mediated cytotoxicity (ADCC). Protocols have been developed for clinical applications of primary NK cells, the NK-92 cell line, or induced pluripotent stem-derived NK cells. ${ }^{3-7}$ Recently, genetically engineered NK cells have been suggested as a promising alternative vehicle for chimeric antigen receptor (CAR)-mediated cancer immunotherapies. ${ }^{7-10}$ Similarly, NK-92 were engineered with high affinity FCR which enables much higher ADCC compared with the more prevalent low affinity FcR. ${ }^{11}$

CARs or FcR+monoclonal antibodies (mAbs) can enable efficient retargeting of NK cells toward any surface antigen on cancer cells and, on ligation, provide strong activating signals to NK cells. After encountering a susceptible target, NK cells mediate directed cytotoxicity by exocytosis of lytic granules with effector molecules (eg, perforin and granzymes) ${ }^{12}{ }^{13}$ One of the first measurable steps after NK cell activation is granule convergence, that is, rapid relocation of lytic granules toward the microtubule-organizing 
center (MTOC). ${ }^{14}$ Subsequently, the MTOC and converged lytic granules become polarized toward the point of NK and tumor cell contact, termed the immunological synapse (IS).$^{15}$ Lytic enzyme-containing granules are then released at the IS, causing tumor cell death. The critical steps leading to NK cell granule release are tightly regulated. ${ }^{16}$ Convergence of NK cell lytic granules can be triggered by the adhesion molecule Lymphocyte functionassociated antigen 1 (LFA-1) in a dynein-dependent manner, ${ }^{14}$ whereas the magnitude of granule polarization depends on further activating signals from receptors such as FcR, 2B4 or NKG2D, among others, controlled by kinesin- $1{ }^{17-20}$ CD16 provides instructive signals for degranulation without polarization in resting NK cells. ${ }^{18}$ Tight regulation of these highly cytotoxic granules is crucial for maximal on-target efficiency and minimal offtarget side effects of NK cells. ${ }^{21}$

Despite recent advances in our understanding of the mechanistic steps leading to effective NK cell cytotoxicity, little is known about granule convergence and polarization in cases where cancer cells have developed escape mechanisms conferring resistance toward NK cellmediated killing. In particular, it is unclear at what step the machinery leading to lytic enzyme exocytosis may be interrupted in cases of tumor cell resistance. Acquisition of NK-resistance by cancer cells results from many genetic and epigenetic changes that can cause a general loss of the target cell adhesion properties required for immune synapse establishment, NK cell activation and ultimately target cell cytotoxicity. ${ }^{22}$ Several mechanisms of tumor escape from NK cell-mediated killing have been reported, including downregulation of activating ligands $\mathrm{s}^{23}$ and upregulation of inhibitory ligands ${ }^{24} 25$ on tumor cells. Additionally, checkpoint molecules can allow tumor escape from NK cell surveillance ${ }^{26}$ and conversely, blockage of inhibitory signals such as the NKG2A-HLA-E axis can elicit cytotoxic NK cell responses in otherwise resistant tumors. ${ }^{27}$

Tumor cell resistance can be reportedly overcome by NK cell retargeting through CARs or ADCC. ${ }^{11}{ }^{28}$ However, it is unknown how NK cell retargeting to tumor cells contributes to the degranulation machinery, and which steps are critical for rendering tumor cells sensitive to NK cell-mediated killing. Here, we investigated what stage of the hierarchical degranulation cascade may be interrupted during an encounter between NK cells and resistant tumor targets, and the extent to which retargeting by therapeutic antibodies and CARs may restore the lytic machinery.

We performed time-lapse confocal live-cell imaging (LCI) to systematically analyze the hierarchy of granule clustering and polarization leading to lytic granules exocytosis. We used the NK cell line NK-92, which maintains many biological functions of primary NK cells, ${ }^{29}$ and an NK-resistant, ErbB2 (HER2)-positive breast cancer cell line. Imaging was performed in the presence and absence of ErbB2-targeted killing by either ADCC using the high-affinity FcR isoform-expressing (haNK) cells ${ }^{11}$ with Herceptin antibody, or by CAR using the ErbB2targeted CAR-expressing NK-92/5.28.z cells. ${ }^{30}$ We found that NK cells that encountered NK-resistant breast cancer cells exhibited a failure of granule polarization, but not of granule clustering. Retargeting by $\mathrm{CAR}$ or the $\mathrm{mAb} / \mathrm{FcR}$ axis rescued granule polarization and, thereby, cytotoxic activity toward otherwise resistant target cells.

\section{MATERIALS AND METHODS}

\section{Cells and cell culture}

The established human NK cell line NK-92 was provided by H.G. Klingemann (Chicago, Illinois, USA). ${ }^{29}$ NK-92/5.28.z cells were previously generated. ${ }^{28}$ The haNK cells, constructed for self-production of interleukin (IL)-2, were provided by NantKwest, Inc. (Culver City, California, USA). ${ }^{11}$ NK cell lines were cultured in X-vivo 10 medium (Lonza) containing 5\% heat-inactivated human AB Plasma (German Red Cross Blood Donation Service North-East, Dresden, Germany), $100 \mathrm{IU} / \mathrm{mL}$ penicillin and $100 \mu \mathrm{g} / \mathrm{mL}$ streptomycin (Merck//Biochrom), referred to as complete X-vivo 10 medium. NK-92 and NK-92/5.28.z cells were additionally supplemented with $500 \mathrm{IU} / \mathrm{mL}$ recombinant human IL-2 (Proleukin; Novartis Pharma).

K562 and MDA-MB-453 cells were purchased from American Type Culture Collection (Manassas, VA, USA). K562 cells were cultured in RPMI 1640 (Merck/ Biochrom) supplemented with $10 \%$ heat-inactivated fetal bovine serum (HI-FBS, Merck/Biochrom), $2 \mathrm{mM}$ L-glutamine (Merck/Biochrom), $1 \mathrm{mM}$ non-essential amino acids (Merck/Biochrom), $1 \mathrm{mM}$ sodium pyruvate (Merck/Biochrom), $100 \mathrm{IU} / \mathrm{mL}$ penicillin and $100 \mu \mathrm{g} /$ $\mathrm{mL}$ streptomycin. MDA-MB-453 cells were cultured in Dulbecco's Modified Eagle's Medium (DMEM) (Merck/ Biochrom) with 10\% HI-FBS (Merck/Biochrom), $2 \mathrm{mM}$ L-glutamine (Merck/Biochrom), $100 \mathrm{IU} / \mathrm{mL}$ penicillin and $100 \mu \mathrm{g} / \mathrm{mL}$ streptomycin.

All cells were cultured at $37^{\circ} \mathrm{C}$ in a humidified atmosphere with $5 \% \mathrm{CO}_{2}$, and routinely checked for $\mathrm{Myco-}$ plasma contamination.

\section{Europium TDA (EuTDA) cytotoxicity assay}

We determined the specific cytotoxicity of the NK-92 cell lines toward target cells using a Europium (EuTDA) cytotoxicity assay (DELFIA, PerkinElmer), following the manufacturer's protocol. Briefly, target cells were loaded with an acetoxymethyl ester of the fluorescenceenhancing ligand (BATDA; Perkin Elmer), and then coincubated in triplicate at 10000 cells/well with effector cells, with or without Herceptin $(2 \mu \mathrm{g} / \mathrm{mL}$; Roche $)$, at the indicated E:T ratios. After a 2-hour coincubation, supernatants were collected for measurement of the fluorescent signal reflecting target cell lysis, using a VICTOR X4 fluorometer (PerkinElmer). Specific lysis was calculated using the standard formula.

\section{Live-cell imaging}

Target cells were seeded in an 8-well $\mu$-slide (Ibidi) at $3.57 \times 10^{4}$ cells/well. MDA-MB- 453 cells adhered for $90 \mathrm{~min}$ 
at $37^{\circ} \mathrm{C}$. $\mathrm{K} 562$ cells were attached to wells coated with antiCD235a (GA-R2; BD Biosciences) during a 15 min incubation at $37^{\circ} \mathrm{C}$. Non-attached cells were washed out, and attached cells stained with CellMask Deep Red plasma membrane stain $(10 \mu \mathrm{g} / \mathrm{mL}$; Thermo Fisher Scientific) for $10 \mathrm{~min}$ at $37^{\circ} \mathrm{C}$. Cells were washed $3 \times$ and maintained in complete Xvivo-10 medium without IL-2 until acquisition. Effector cells were stained with $2 \mu \mathrm{M}$ LysoTracker Red DND-99 (Thermo Fisher Scientific) for $30 \mathrm{~min}$ at $37^{\circ} \mathrm{C}$, and then added to the target cells immediately before the start of imaging at a 3:1 E:T ratio $\left(1.07 \times 10^{5}\right.$ cells/well $)$. LCI was performed in a total volume of $200 \mu \mathrm{L}$ complete Xvivo-10 medium without IL-2, containing $1 \mu \mathrm{M}$ SYTOX Blue (Thermo Fisher Scientific) for dead cell discrimination, at $37^{\circ} \mathrm{C}$ and $5 \% \mathrm{CO}_{2}$.

Time-lapse imaging was performed using an Olympus IX-83 spinning disk confocal microscope equipped with a Yokogawa CSU-X1 spinning disk, and an Olympus Plan Apo60 $\times 1.42 \mathrm{NA}$ oil-immersion objective. Images were acquired every $3 \mathrm{~min}$ for $6-9$ hours, in multiple $\mathrm{z}$-axis planes for fluorescent channels, and a single z-plane for transmitted light. Time point zero marks the start of image acquisition. For steady-state effector cell analysis, we acquired individual images of different positions. Samples were excited by an ultraviolet laser at $405 \mathrm{~nm}$, diode-pumped solid-state (DPSS) lasers at $488 \mathrm{~nm}$ and $561 \mathrm{~nm}$, or a diode laser at $640 \mathrm{~nm}$. Emission was detected using an iXon Ultra 897 EMCCD camera, controlled by AndoriQ V.3.2 software.

\section{Image analysis}

Images were analyzed using Fiji/ImageJ (National Institutes of Health) and Imaris (BitPlane). Details of image analysis are provided in online supplemental material.

\section{Statistical analysis}

Statistical analyzes were performed using GraphPad Prism V.7 (Graphpad Software). Prestimulated and poststimulated NK cells were analyzed with a paired twotailed Student's t-test. Other data were analyzed using an unpaired two-tailed Student's t-test. A $p \leq 0.05$ was considered statistically significant.

\section{RESULTS}

\section{Tracking NK cell killing and conjugate formation by LCI}

Through LCI, we analyzed NK-cancer cell interactions in real-time. We used the NK-92 cell line, which is functionally and phenotypically similar to primary NK cells, except that NK-92 cells do not express HLA-recognizing KIRs. ${ }^{29}$ Therefore, the NK-92 model enabled us to study cancer resistance toward NK cell cytotoxicity in the absence of HLA-mediated NK inhibition. We used the MDA-MB-453 breast cancer cell line as a NK cellresistant model, and the K562 cell line as a NK cellsensitive model. ${ }^{28} 31$

First, we tested the suitability of confocal LCI for measuring NK cell cytotoxicity as a functional indicator.
Target cells were fluorescently stained with CellMask for discrimination from NK cells, and both cell types were cocultured with SYTOX Blue reagent for dead cell discrimination. Cell images were captured every $3 \mathrm{~min}$, over 6-9 hours, using spinning disk confocal microscopy (figure 1A). As expected, K562 cells were killed by NK-92, while MDA-MB-453 cells remained unaffected (figure 1B; online supplemental videos 1 and 2).

We next applied the established real-time method and analyzed the kinetics of killing events, as measured by SYTOX Blue uptake. K562 killing events continuously increased over time and recapitulated a standard Europium-based release assay, while MDA-MB-453 cells remained intact (figure 1C,D). We then investigated conjugate formation between NK and tumor cells. Our system enabled tracking the formation of each cell-cell conjugate over time, and this non-invasive method allowed measurement of weaker cell-cell interactions compared with flow cytometry-based methods. We defined stable conjugation as NK-tumor cell contact that lasted over 15 min. Interestingly, stable conjugate formation did not significantly differ between the susceptible and resistant cell lines (figure 1E), indicating that tumor cells that were resistant to NK cell killing still formed stable conjugates with effector cells.

\section{Granule polarization, but not granule clustering, reflects MDA- MB-453 cell resistance toward NK cell cytotoxicity}

Conjugation between NK and target cells is the first step toward NK cell cytotoxicity. ${ }^{16}$ After finding that the lack of NK cell cytotoxicity was not caused by deficient cell conjugation, we next analyzed the movement of cytotoxic granules during the killing process. We first used the K562 cell line to study granule behavior in susceptible tumor cells. NK cell granules were stained with Lysotracker reagent, and live-cell images were acquired by time-lapse confocal microscopy (figure 2A; online supplemental video 3). Our system enabled granule tracking in single cells, following all steps of intracellular granule movement, from conjugation to the final release of the granule content and target cell death. In NK cells that formed stable conjugates with K562 cells, the images were subjected to segmentation analysis (figure 2B; online supplemental video 4) and granule convergence was measured by calculating the distance of individual granules from the granules cluster center as a substitute for MTOC as described previously, ${ }^{21} 32$ and termed 'granule clustering' (figure 2C). We also measured granule polarization, defined by the distance of lytic granules from the IS (figure 2D). As expected, after contact between NK and K562 cells, the granules clustered and polarized toward the IS. Polarized granules subsequently released their content, causing apoptosis of susceptible cells (figure 2A-D).

We next investigated granule movement in NK cells coincubated with the resistant MDA-MB-453 cells. Single-cell tracking revealed that NK cells formed numerous cell contacts and stable conjugations with 
A

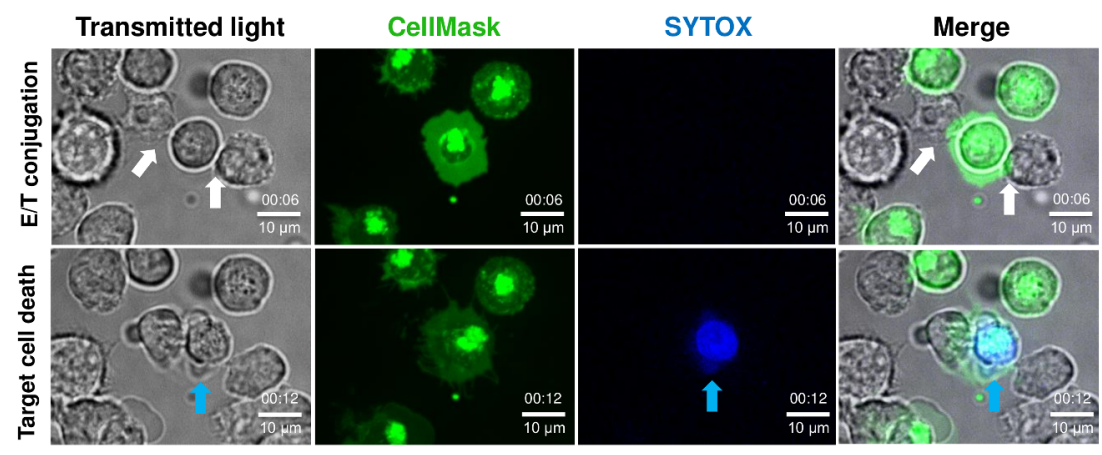

B Target / Dead cell

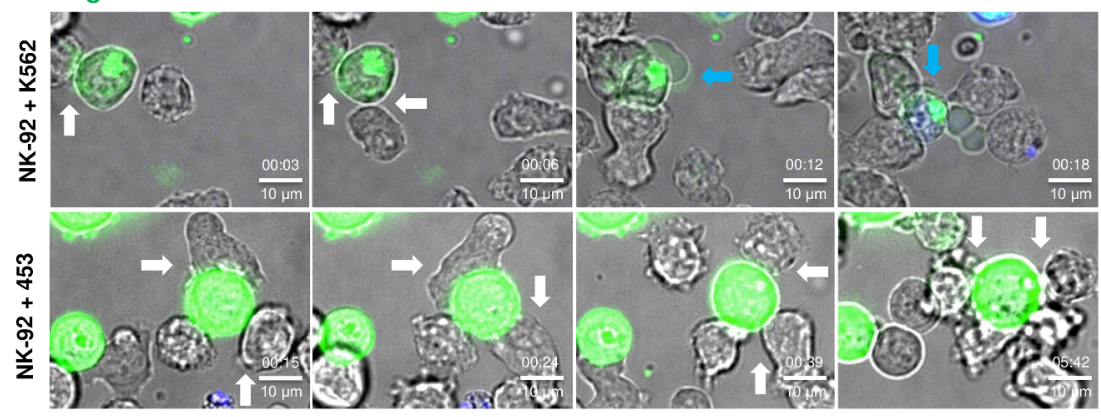

c

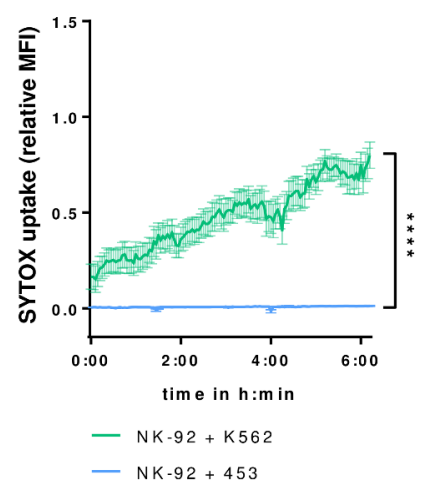

D

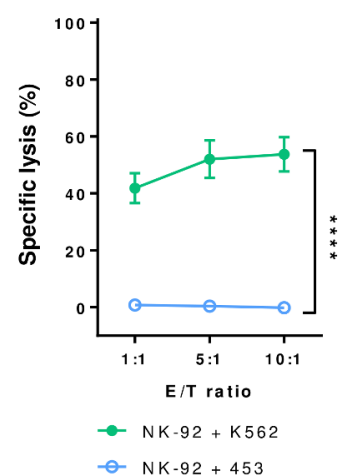

E

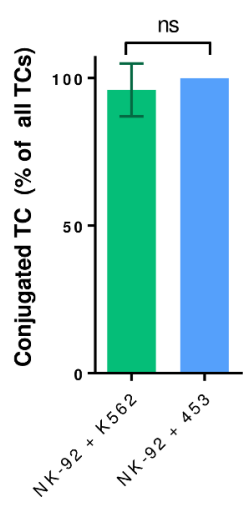

Figure 1 NK cells form stable conjugates with resistant tumor cells. (A) Live-cell confocal microscopy of NK-92 and K562 cells. Target cells are stained with CellMask (green), and dead cells visualized by sytox reagent (blue). Single channels for transmitted light, each fluorescent channel and a merge of all channels are shown for two time points: early conjugation (upper row, white arrows show conjugates) and after target cell death (bottom row, the blue arrow shows a dead target). (B) Time-lapse imaging of NK-92 interaction with susceptible K562 cells (upper image sequence) or the resistant breast cancer cell line MDAMB-453 (453; bottom image sequence). Conjugations are indicated by white arrows, and target cell death by blue arrows. Time in hh:mm. (C) Sytox uptake of target cells in conjugates over time is shown as the mean fluorescence intensity (MFI) relative to maximum MFI. Data from at least 3 independent experiments done on separate days are shown (13 conjugates for K562 and 19 conjugates for MDA-MB-453 were analyzed). (D) NK-92 and target cells were cocultured at the given E/T ratios for 2 hours, and specific cytotoxicity was measured by Europium-based cytotoxicity assay. Mean values \pm SEM are shown. (E) Conjugate formation was monitored during live-cell imaging. Target cells (TC) stably conjugated to NK cells are plotted as a percentage of all observed target cells ( $n=26$ for K562, $n=21$ for MDA-MB-453). Data represent at least 3 independent experiments done on separate days. Mean values \pm SD are shown. NK, natural killer.

target cells (figure 3A; online supplemental video 5) that might be explained by LFA-1/intercellular adhesion molecule 1 (ICAM-1) interaction (figure 3D), but were unable to kill them. Within an individual NK cell, we observed that the magnitude of lytic granule clustering significantly differed before and after conjugation, suggesting that NK cells are able to respond to the cancer cell by granule clustering but are unable to undergo significant polarization (figure 3B,C). We concluded that MDA-MB-453 tumor cell resistance was due to a failure of granule polarization, but not of granule clustering.

\section{Retargeted NK cells overcome resistance of breast cancer cells}

We and others have shown that retargeting NK cells toward resistant tumors by CAR or mAbs can eliminate initially resistant solid tumor cells. ${ }^{11} 28{ }^{30}$ However, the mechanistic basis of cytotoxicity processes after retargeting is poorly understood. Therefore, we next investigated granules behavior 
A

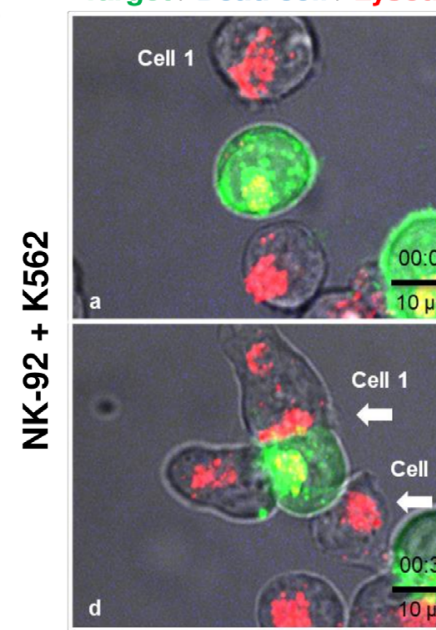

Target / Dead cell / Lysotracker

B
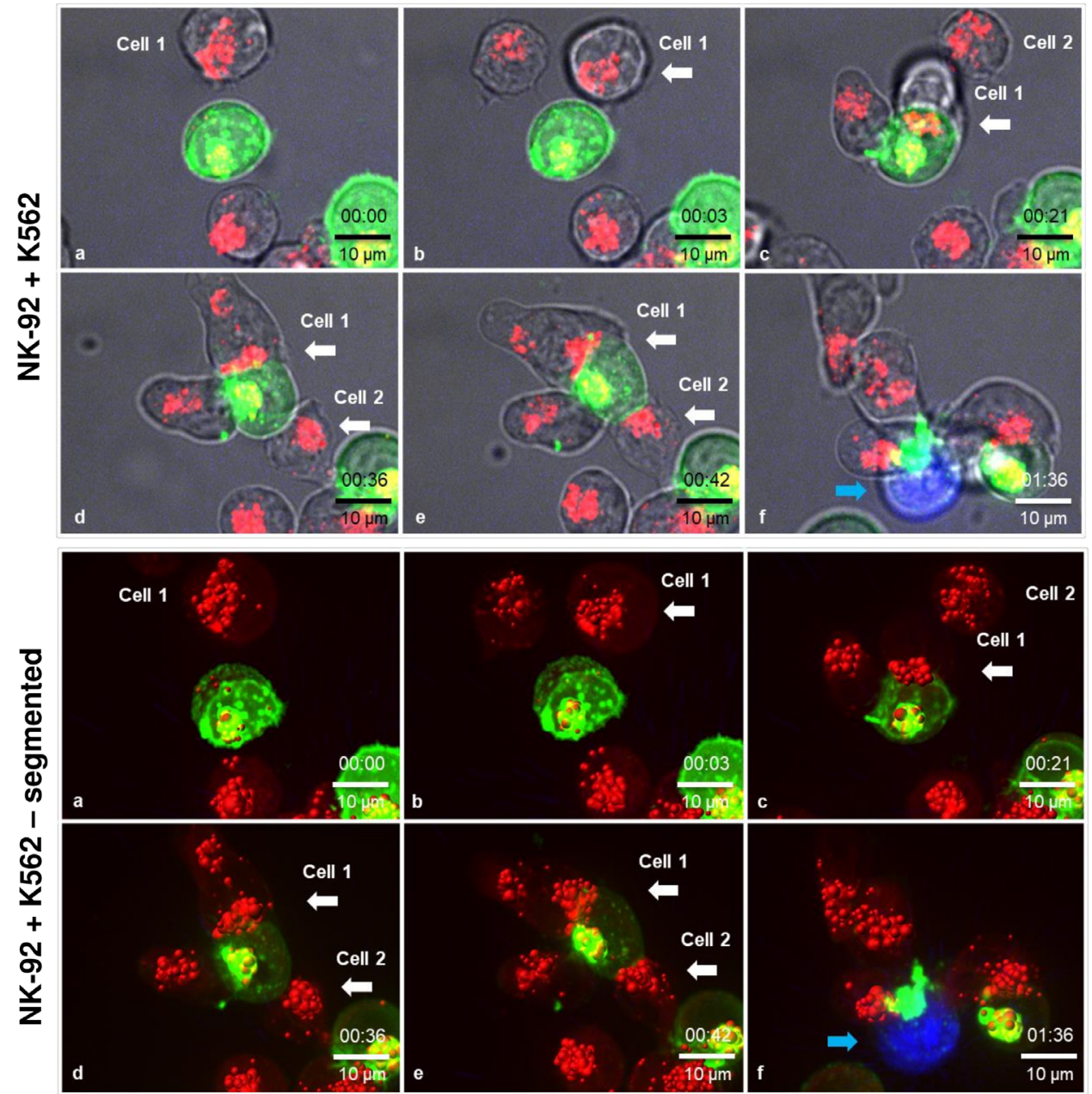

C

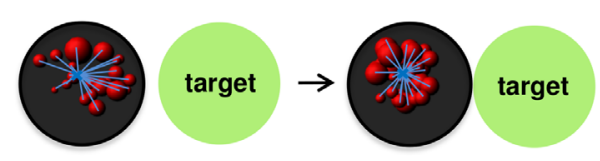

D
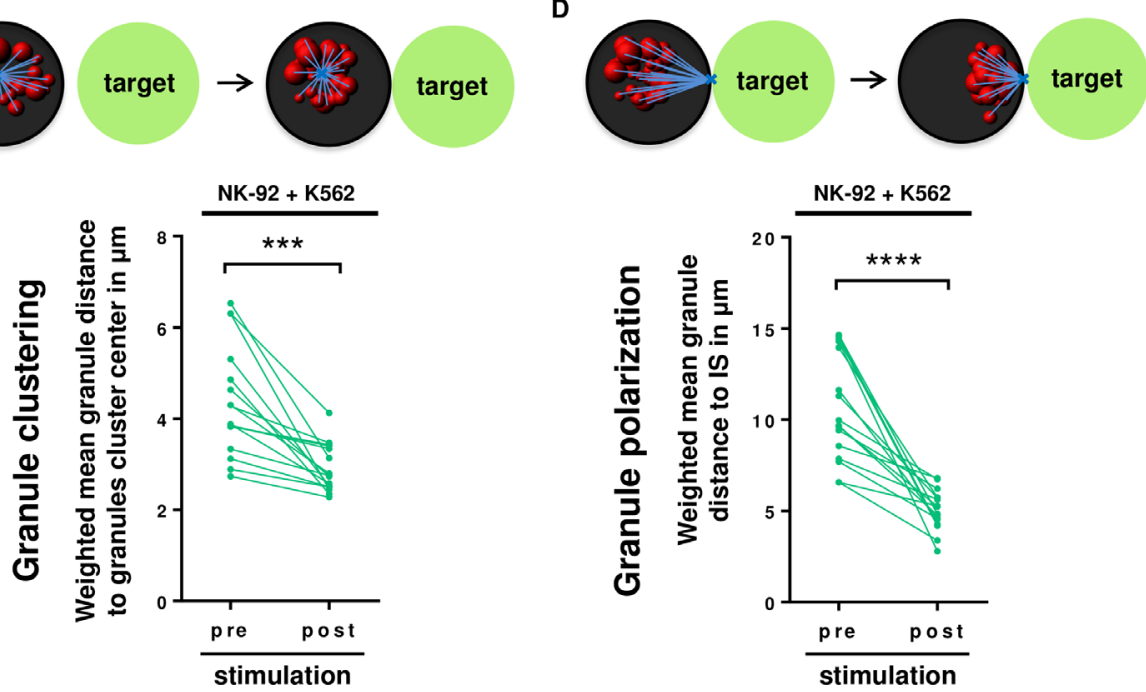

Figure 2 NK cells cluster and polarize lytic granules after contact with the susceptible cell line K562. (A) Lytic granules of NK92 were stained with Lysotracker (red), and live-cell imaging of NK-92 cocultured with susceptible K562 cells was performed. White arrows show conjugates, and blue arrows show dead cells. Representative images are shown. Time in hh:mm. (B) Granules were further segmented using Imaris software for quantification. (C) Lytic granule clustering was measured as the mean distance of single granules to the granules cluster center (replacing the microtubule-organizing center). (D) Granule polarization was measured as the mean distance of single lytic granules to the immunological synapse (IS), identified as the conjugation point of NK and target cells in 3D reconstructed images. Granule clustering and polarization in each cell was followed and analyzed before (pre) and after (post) stimulation with target cells. Only cytotoxcic NK cells that formed conjugates were counted. Each dot represents the mean of granules per cell per experiment. Data represent at least 3 independent experiments. 3D, 3 dimensional; NK, natural killer. ${ }^{* * *} \mathrm{P}<0.001,{ }^{* * *} \mathrm{P}<0.0001$. 
A Target/ Dead cell / Lysotracker

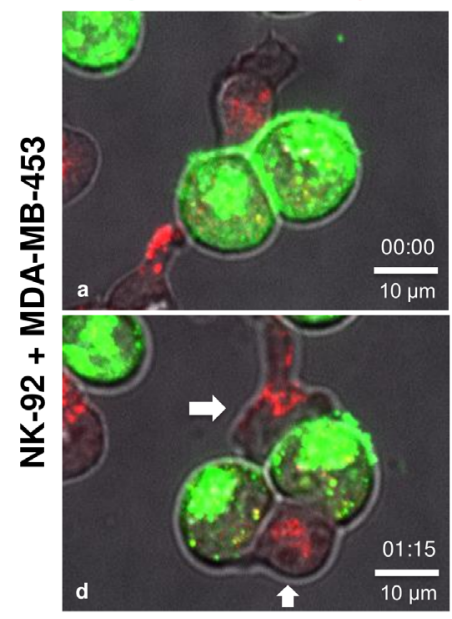

B

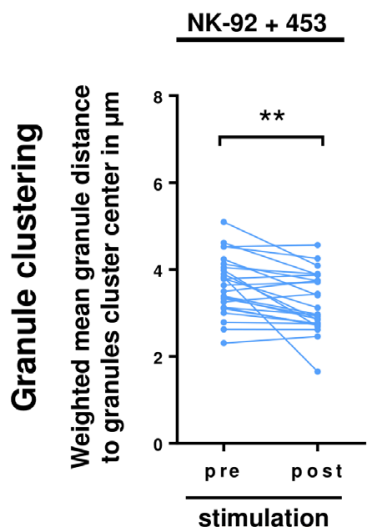

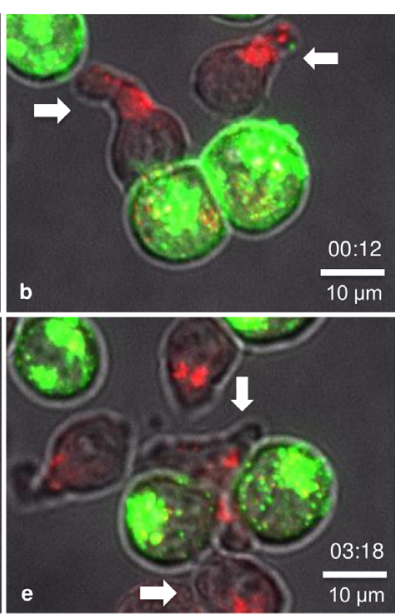

C

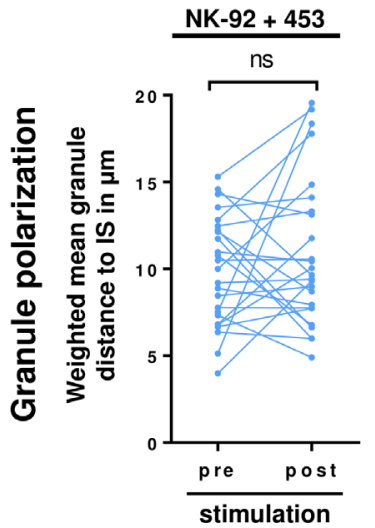

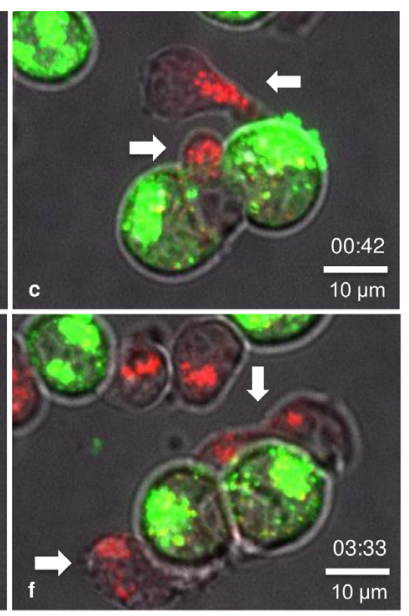

D

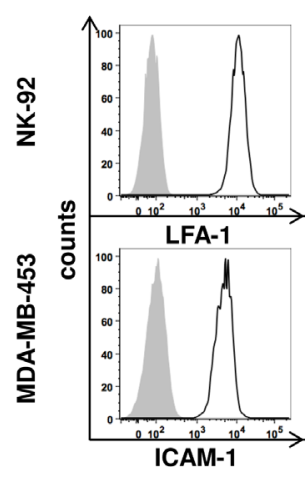

Figure 3 NK cell-resistant tumor cells induce clustering but not polarization of NK cell lytic granules. (A) Time-lapse imaging of NK-92 cocultured with the resistant MDA-MB-453 cell line. White arrows indicate conjugations of NK-92 with target cells. Representative images are shown. Time in hh:mm. (B,C) Granule clustering (B) and granule polarization (C) were quantified preconjugation and postconjugation in the same manner as in figure 2. Combined data from at least three independent experiments. (D) Histograms show LFA-1 expression in NK-92 cells and ICAM-1 expression in MDA-MB-453 cells, analyzed by flow cytometry. Corresponding isotype controls are depicted in gray. Representative data from at least 3 independent experiments are shown. IS, immunological synapse; NK, natural killer; ns, not significant. ${ }^{* \star} \mathrm{P}<0.01$.

in retargeted NK cells. Since MDA-MB-453 cells express the ErbB2 antigen (figure 4A), we chose to work with an ErbB2-CAR-expressing NK-92 cell line (NK-92/5.28.z) ${ }^{28}$ and a haNK FcR-expressing NK-92 cell line ${ }^{11}$ combined with the therapeutic anti-ErbB2 antibody Herceptin (figure 4B). Consistent with previous studies, ${ }^{11} 28$ both retargeted NK-92 cell lines exhibited cytotoxicity toward otherwise resistant MDA-MB-453 targets, as measured by Europium-based release assay (figure 4C).

We performed LCI (SYTOX uptake) over a 9-hour period to characterize the kinetics of the cytotoxicity of NK-92/5.28.z and haNK +Herceptin (ADCG) toward MDAMB-453 (figure 4E,F; online supplemental videos 6 and 7). The data recapitulated our results with the Europium-based release assay, while revealing that ADCC had a slower onset compared with CAR-mediated cytotoxicity (figure 4D). In some cases, we observed serial killing, where one NK cell killed the first tumor cell, and then repolarized toward and killed a second tumor cell without interrupting contact with the first dead target (figure $4 \mathrm{E}$; online supplemental video
6). We concluded that both CAR- and mAb-retargeted NK cells could overcome the resistance of MDA-MB-453 cells, although the kinetics differed.

\section{Retargeting of NK cells rescues granules polarization, leading to killing of resistant tumor cells}

We next examined the lytic granule clustering status in the second-generation CAR or haNK FcR expressing NK cells in steady state. For consistency with previous sample preparation and to avoid possible fixation artifacts, we performed live-cell confocal imaging of NK-92, NK-92/5.28.z and haNK cells without activation stimuli, and compared the granule clustering status of transgenic NK-92 cells to the parental cell line (figure 5A). Our data revealed that the lytic granules of NK-92/5.28.z and haNK cells did not show higher spontaneous clustering than those of the parental NK cells (figure 5B).

To further explore the cytolytic granule movement in NK-92/5.28.z and haNK +Herceptin after contact with resistant MDA-MB- 453 cells, we measured the granule clustering 
A

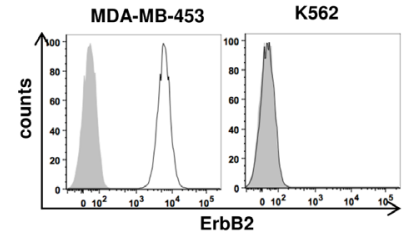

B
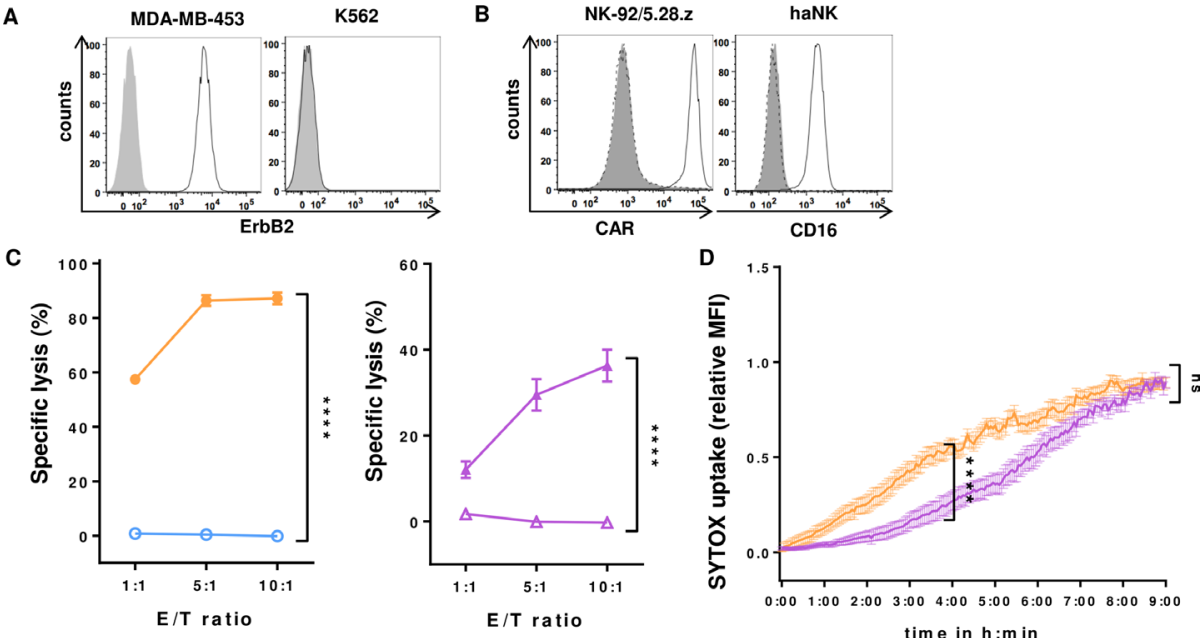

time in $\mathrm{h}: \mathrm{m}$ in

$\rightarrow$ NK-92/5.28.z+453

\pm haNK + Herceptin

- NK-92+453

$\triangle$ haNK - Herceptin

- NK-92/5-28 z+MDA-MB-453

- haNK/Herceptin + MDA-MB-453

E Target / Dead cell / Lysotracker

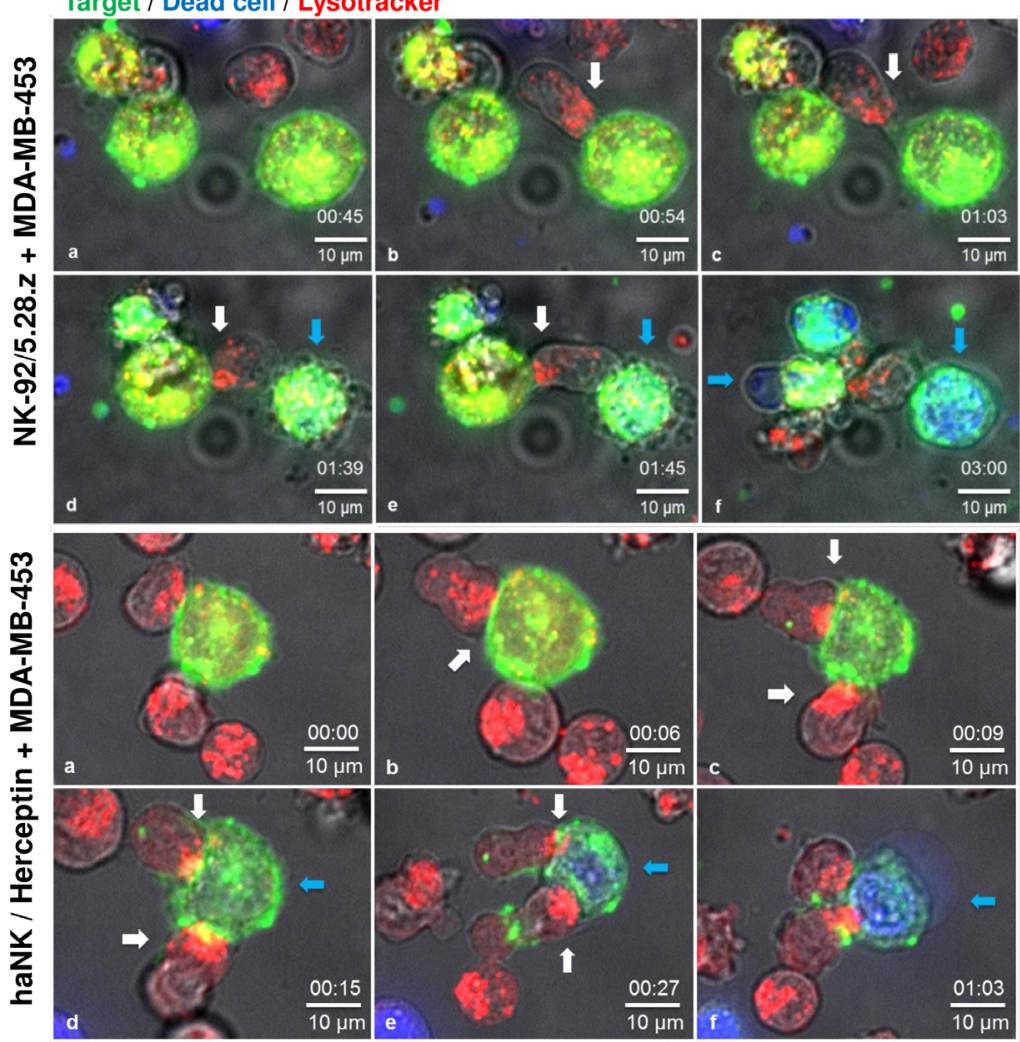

Figure 4 Both CAR-retargeted and FcR-mAb-retargeted NK cells overcome cancer cell resistance. (A) Flow cytometry analysis of ErbB2 expression in MDA-MB-453 and K562 cancer cell lines. isotype controls are shown in gray. (B) CAR expression on NK-92/5.28.z (left) was detected by ErbB2-Fc combined with anti-Fc secondary antibody. FcR on haNK (right) was stained with anti-CD16 antibody. Dashed lines indicate stained parental NK-92 cells, and filled gray areas indicate unstained controls. Representative data from at least 3 independent experiments are shown. (C) Specific cytotoxicity of NK-92/5.28.z and haNK+Herceptin toward MDA-MB-453 was measured by Europium-based assay after $2 \mathrm{~h}$ co-culture. NK-92 and haNK without Herceptin were used as negative controls. (D) Cytotoxicity of NK-92/5.28.z and haNK+Herceptin toward MDA-MB-453 was monitored by live-cell imaging (SYTOX uptake) over time. Statistical analysis is shown for the 4 hour and 9 hours coincubation time points. Data represent at least 3 independent experiments. Mean values \pm SEM are shown. $n=25$ (NK-92/5.28.z) and 15 (haNK) conjugates. (E) Time-lapse imaging of NK-92/5.28.z with MDA-MB-453. (a) Unconjugated NK cell with dispersed lytic granules. (b-e) An NK-92/5.28.z cell binds to two target cells, clusters and polarizes its lytic granules (white arrows) and (d-f) kills the cancer cells (blue arrows). (F) Time-lapse imaging of haNK+Herceptin with MDA-MB-453. (A) Two haNK cells form a conjugate with a target cell. (B-E) Granule clustering and polarization of both haNK cells occurs toward the conjugation points (white arrows). (D-F) The target cell turns blue, indicating cell death (blue arrows). Time in hh:mm. Representative images of at least four independent experiments are shown. CAR, chimeric antigen receptor; FcR, Fc receptors; haNK, high-affinity natural killer; ns, not significant; ${ }^{\star \star \star \star} \mathrm{P}<0.0001$. 
A

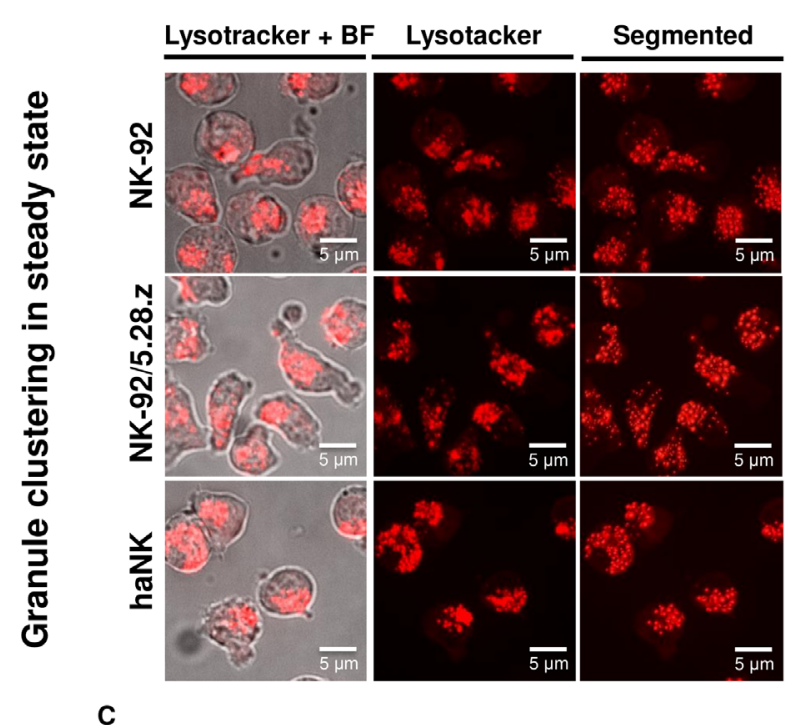

C
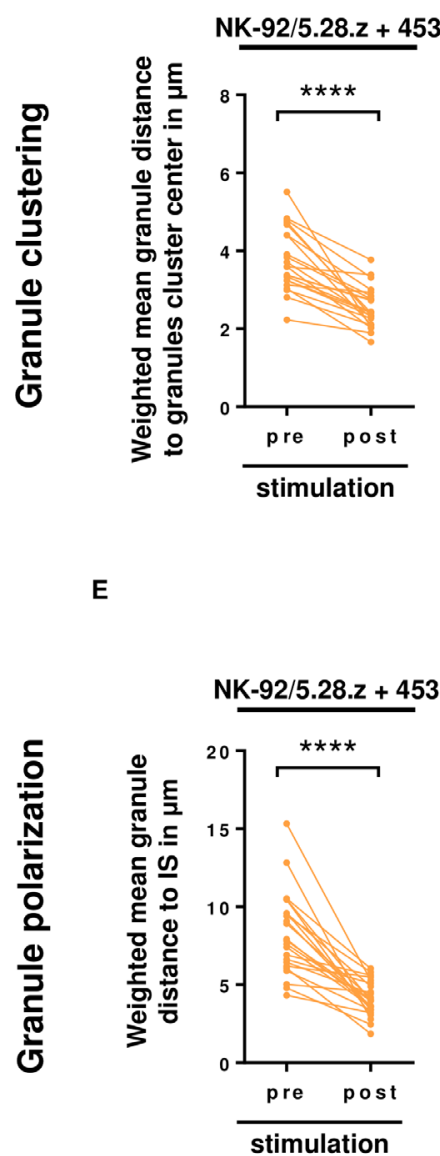

B

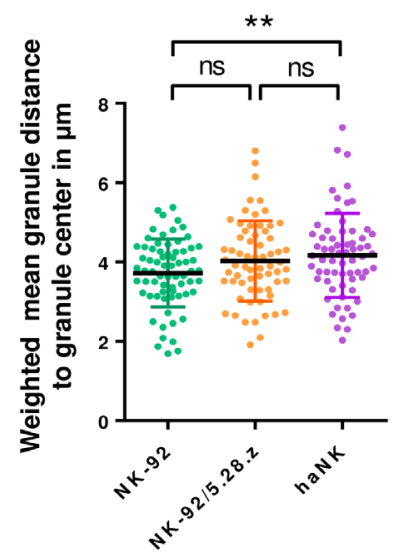

D
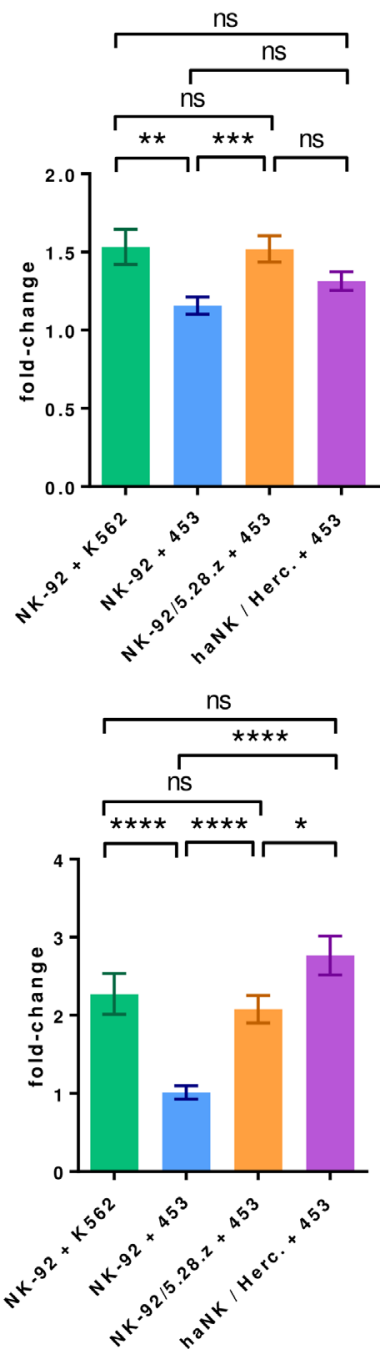

Figure 5 Erbb2 retargeting induces granule polarization on stimulation by resistant tumor cells. (A) Live-cell imaging showing granule distribution of NK-92, NK-92/5.28.z, and haNK cells in steady state. representative images are shown. (B) Quantification of granule clustering status of NK-92, NK-92/5.28.z, and haNK cells in steady state. Mean granule distances toward granules cluster center $\pm S D$ from 2 independent experiments are shown. (C, E) Quantification of the live-cell imaging data: granule clustering $(C)$ and granule polarization toward the is $(E)$ in NK-92/5.28.z and haNK toward the immunological synapse after stimulation by MDA-MB-453 target cells. (D, F) Quantification of granule clustering (D) and granule polarization (F) in parental NK-92 and retargeted NK-92 lines after activation by the indicated targets displayed as fold-change. Data in C-F represent at least three independent experiments. Mean values \pm SEM are shown. haNK, high-affinity natural killer; IS, immunological synapse; ns, not significant; ${ }^{\star} \mathrm{P}<0.05,{ }^{\star \star} \mathrm{P}<0.01,{ }^{* \star *} \mathrm{P}<0.001,{ }^{\star \star \star \star} \mathrm{P}<0.0001$. 
within each NK cell that formed stable contact with a tumor cell, before and after conjugate formation (figure 5C). As expected, both retargeted NK cell lines showed significant granule clustering in response to contact with resistant MDA-MB-453 cells. However, plotting the fold-change in clustering degree before and after conjugation revealed that NK-92/5.28.z+MDAMB-453 and NK-92 +K562 exhibited similar clustering and that both were significantly stronger than NK-92 +MDAMB-453 cells (figure 5D). While haNK + Herceptin also exhibited a stronger granule clustering than NK-92 +MDAMB-453, it did not reach significance. This suggested that granule clustering degree could be modulated based on the nature of the activation signal. We next investigated granule polarization of NK-92/5.28.z and haNK cells+Herceptin, and found that both cell lines displayed strong polarization after contact with MDA-MB-453 cells, in contrast to parental NK-92 cells (figures 5E,F and 3C). Thus, the retargeting of NK cells by CAR or mAb enabled NK cells to polarize cytotoxic granules toward otherwise resistant cancer cells, and to thereby activate the lytic machinery leading to target cell death.

\section{Immune synapse termination in antibody-based retargeted NK cells}

The last step in NK cell killing is detachment from the target cell, but little is known about how retargeted NK cells terminate the immune synapse. Under our experimental conditions, both NK-92/5.28.z and haNK+Herceptin showed high rates of conjugate formation $(87 \% \pm 6 \%$ and $94 \% \pm 6 \%$, respectively) during 9 hours of time-lapse imaging (figure 6A). Using a flow cytometry-based conjugation assay, we detected less conjugates in all samples but in consistency with the microscopy data, we observed no significant difference between NK-92 and retargeted versions after coculture with MDA-MB-453 (online supplemental figure S2).

We next investigated the duration of NK-target conjugation on establishment of stable contact. Although NK-92 cells formed stable conjugates with resistant MDA-MB-453 cancer cells, binding was terminated in $56 \%$ of cases. In contrast, CAR-retargeted and mAb-retargeted NK cells formed stable conjugations that lasted until the end of acquisition time in all cases, except for one termination each observed among NK-92/5.28.z (1/27, 4\%) and haNK $(1 / 14,7 \%)$ (figure 6B,C). Our detailed investigation of the termination process of NK-92/5.28.z and haNK cells revealed that they did not detach by releasing the receptor binding, but rather a piece of target cell membrane was teared off and remained bound to the NK cell (online supplemental figure S1; online supplemental videos 8 and 9). Thus, both CAR- and mAbretargeted NK cells showed a high rate of strong-binding permanent conjugations.

\section{Kinetics of granule polarization and cytotoxicity in retargeted NK cells}

To better understand the killing efficiency of resistant target cells by retargeted NK cells on a single cell level, we measured NK cell contacts required to induce cytotoxicity. MDA-MB-453 exposed to CAR-retargeted NK cells were killed after only $1.1 \pm 0.1$ contacts, while resistant target cells exposed to ADCC-retargeted NK cells required $2.1 \pm 0.3$ contacts, and susceptible K562 targets exposed to NK cells required $1.6 \pm 0.3$ contacts (figure 6D), which was consistent with the killing efficiency (figure 6E). We further tracked each cell forming a stable conjugate with a target cell, and measured the kinetics of processes leading to cell lysis. CAR-retargeted NK cells exhibited faster polarization $(5 \pm 1 \mathrm{~min})$ than NK cells activated by natural receptors $(9 \pm 2 \mathrm{~min})$ or ADCCretargeted NK cells $(13 \pm 2 \mathrm{~min})$ (figure $6 \mathrm{~F}$ ). Importantly, for CAR-retargeted NK cells, the time interval between granule polarization and target cell death was significantly shorter $(5 \pm 1 \mathrm{~min})$ compared with natural killing $(36 \pm 12 \mathrm{~min})$ or ADCC $(54 \pm 20 \mathrm{~min})$ (figure $6 \mathrm{G})$. Killing duration, defined as the time between cell contact and cell death, was significantly shorter with CAR-retargeted NK cells $(10 \pm 1 \mathrm{~min})$ compared with natural cytotoxicity $(43 \pm 12 \mathrm{~min})$ or ADCC $(66 \pm 21 \mathrm{~min})$. This time difference can largely be explained by prolonged post-polarization steps in natural cytotoxicity and ADCC (figure $6 \mathrm{H}$ ). Thus, different NK cell activation receptors lead to variable polarization velocities and killing kinetics.

\section{Signaling pathways involved in natural and retargeted NK cell cytotoxicity}

To further investigate which signaling pathways are involved in the CAR-retargeted or ADCC-retargeted lysis of otherwise resistant MDA-MB-453 cells, we incubated NK-92, NK-92/5.28.z and haNK+Herceptin with sensitive K562 or resistant MDA-MB-453 cells, and then analyzed phosphorylation of several signaling proteins in the NK cells by flow cytometry. In NK-92 cells, contact with sensitive K562 cells activated Akt downstream of phosphoinositide 3-kinase (PI3K), as well as phospholipase $\mathrm{C}-\gamma$ $(\mathrm{PLC} \gamma)$ and mitogen-activated protein kinase (MEK)/ extracellular signal-regulated kinase (ERK) pathways (figure 7A,B and online supplemental figure S3). In contrast, contact of parental NK-92 with resistant MDAMB-453 only resulted in activation of the PI3K pathway, but not PLC $\gamma$ and MEK/ERK. On retargeting by CAR or ADCC, however, all three pathways (PI3K, PLC $\gamma$, MEK/ ERK) were activated in the engineered NK cells when in contact with resistant MDA-MD-453. Thereby, even stronger Akt phosphorylation was observed than under conditions of natural cytotoxicity toward K562.

\section{DISCUSSION}

After the promising results of CAR $\mathrm{T}$ cell therapy in selected hematological malignancies, NK cell-retargeting is arising as an alternative strategy with hope for better success in treatment of other cancer types including solid tumors. ${ }^{3-7} 33$ Although NK cells can eliminate certain transformed cells, other tumors escape NK cell-mediated killing. One important cause of tumor resistance toward NK cell cytotoxicity is a lack of NK cell activation due to decreased stimulation of activating receptors or increased stimulation of inhibitory receptors. Recently, retargeting 
A

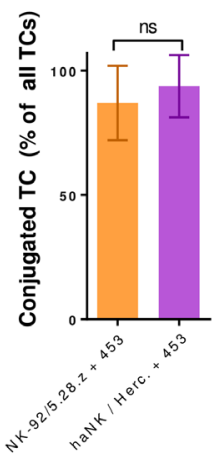

D

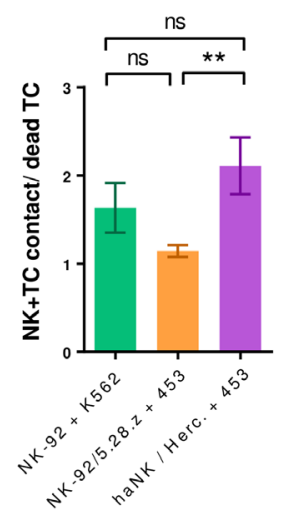

H

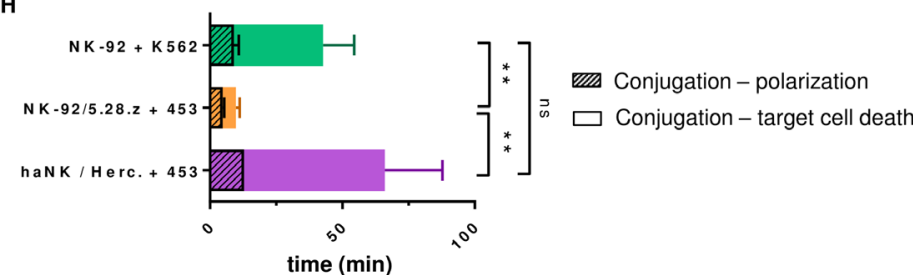

B
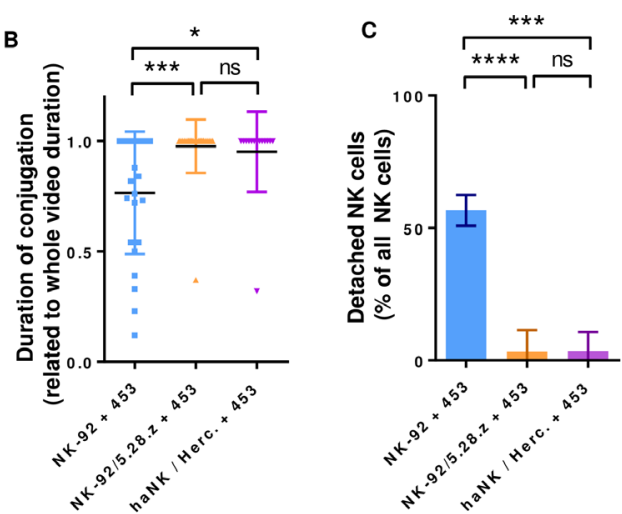

E

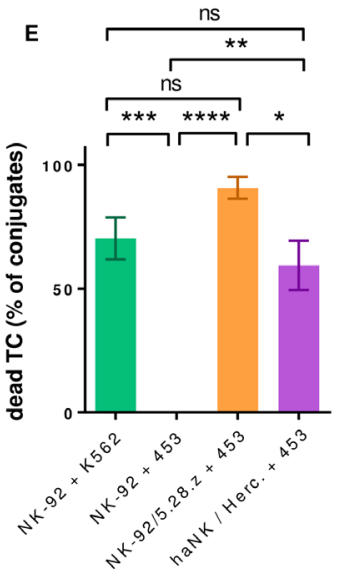

F

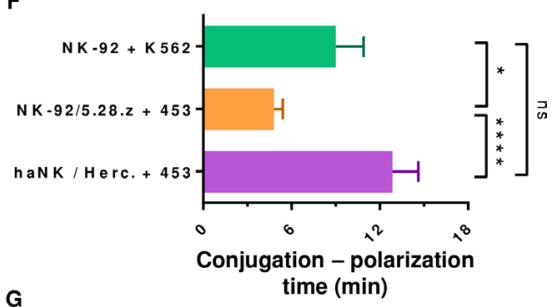

G

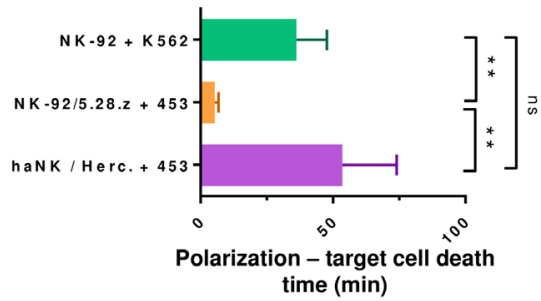

Figure 6 CAR and FcR-mAb retargeted NK cells remain in permanent target cell contact and their different dynamics of steps involved in cytotoxicity correlate with cell killing. Conjugation of NK cells with their target was monitored over time by live-cell imaging. (A) Target cells in stable conjugates (over 15-min duration) as percentage of all target cells. $n=6$ experiments for NK92/5.28.z (48 targets), 4 experiments for haNK (32 targets). (B) Duration of MDA-MB-453 conjugations with NK-92 or retargeted variants. (C) Percentage of all detached NK cells from the MDA-MB-453 cell line. Data represent at least three independent experiments. mean values \pm SD are shown. NK-92, NK-92/5.28.z and haNK were cocultured with susceptible K562 or resistant MDA-MB-453 targets and analyzed by live-cell imaging. (D) Number of contacts required by a single NK cell to successfully kill the given target. (E) Target cells (TC) that formed conjugates with NK cells were analyzed for sytox uptake as a marker for cell death. $(F, G)$ Time period between conjugation and granule polarization $(F)$ or polarization and target cell death $(G)$. (H) Duration of the complete killing process, starting with NK and target cell conjugation, and ending with sytox uptake. The time period until polarization is marked. Data are pooled from at least three independent experiments. Mean values \pm SEM are shown. CAR, chimeric antigen receptor; FcR, Fc receptors; haNK, high-affinity NK; NK, natural killer; ns, not significant; ${ }^{\star} \mathrm{P}<0.05$, ${ }^{\star \star} \mathrm{P}<0.01$, ${ }^{\star \star \star} \mathrm{P}<0.001,{ }^{\star \star \star \star} \mathrm{P}<0.0001$.

through CAR or mAb was found to successfully overcome NK cell resistance. ${ }^{11} 30$ 34-36 Despite rapid progress toward the development of new retargeting approaches, little is known about the role of the intracellular movement of NK cell lytic granules in overcoming resistant tumors. A better understanding of how these processes influence the ability of NK cells to bypass tumor resistance could improve the design of future NK cell retargeting strategies. Here, we investigated NK cell lytic granule clustering and granule polarization toward the IS after conjugation between NK cells and resistant tumor cells. To more closely approximate physiological conditions, we used long-term LCI technology that enabled us to follow the cellular interactions without any disturbances to the cells. To our knowledge, we showed for the first time that NK cells formed long-lasting interactions with resistant cells, and that these interactions still triggered clustering of lytic granules, but failed to trigger granules polarization. 

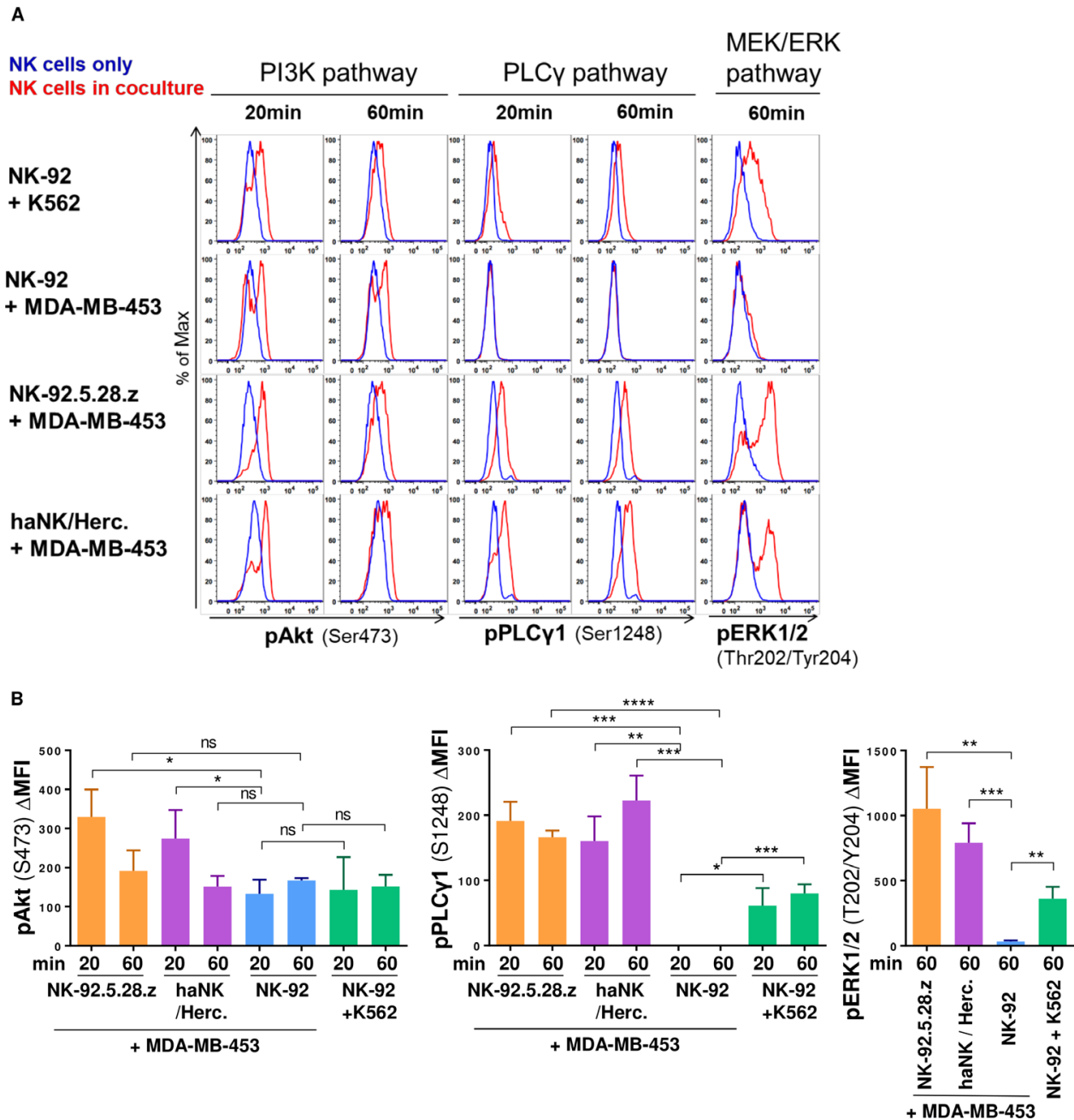

Figure 7 Resistant MDA-MB-453 cells induce PI3K signaling in NK-92 but fail to trigger PLC $\gamma$ or MEK/ERK activation, which is rescued by car or ADCC. NK cells were mixed with cancer cells for the indicated time periods or kept alone. Phosphorylation of the indicated signaling molecules in NK cells was determined by flow cytometry. NK cells were discriminated by CD56 staining. PI3K, PLC $\gamma$ and MEK/ERK pathways were analyzed by assessing pAkt (Ser473), pPLC $\gamma 1$ (Ser1248) and pERK1/2 (Thr202/ Tyr204), respectively. (A) Histograms show in blue NK cells only, and in red NK cells cocultured with the indicated target cells. (B) Mean fluorescence intensity (MFI) data from 3 independent experiments. Mean values \pm SD are shown. ERK, extracellular signal-regulated kinase; MEK, mitogen-activated protein kinase; NK, natural killer; PI3K, phosphoinositide 3-kinase; PLC $\gamma$, phospholipase C- $\gamma$. ns, not significant; ${ }^{\star} \mathrm{P}<0.05,{ }^{* \star} \mathrm{P}<0.01,{ }^{* \star *} \mathrm{P}<0.001,{ }^{* \star \star *} \mathrm{P}<0.0001$.

Retargeting NK cells both by CAR expression or mAb/ ADCC restored NK cell polarization and resulted in killing of the resistant cells.

NK-tumor cell conjugation is considered the first important step at which tumor cells can escape from NK cell killing. Previous studies reported that triggering of inhibitory receptors causes decreased conjugation frequency, ${ }^{37} 38$ and that an ADCC-resistant cell line generated by natural selection formed fewer conjugates with NK cells. $^{22}$ We used LCI to examine the conjugation kinetics of NK cells with resistant targets. Our data suggest that livecell microscopy enables visualization of even weaker interactions as compared with standard flow cytometry-based conjugation assay. Interestingly, all observed NK cells that came in contact with cancer cells formed long-lasting interactions even with targets that they could not kill. Further research is required to elucidate whether binding to resistant cancer cells is only integrin based or involves other molecules, and whether checkpoint inhibitors can disrupt this signal. We hypothesize that this binding enables NK cells to scan diseased cells and search for stronger stimulation, and that on reaching a stronger signal, NK cells are activated and tumor cells are lysed. Previously reported data suggested that stronger activation signals can support stronger intercellular binding, and that those signals can be reversed by inhibitory receptors. ${ }^{37-39}$ Therefore, for the full understanding of NK-target cell interaction, we propose a combined use of both standard conjugation assays to detect strong interactions ${ }^{38}$ and LCI-based conjugation assays to detect weaker physiological interactions as well as conjugation dynamics.

Our data revealed that although NK cells conjugate with resistant MDA-MB-453 cells, they cannot kill them. Thus, we studied the cytotoxicity steps between conjugation and target cell death: lytic granules clustering and polarization. 
A recent study experimentally demonstrated the physiological importance of lytic granule convergence for directed cytotoxicity of NK cells. ${ }^{21}$ To our knowledge, the NK cell granule convergence/clustering status after contact with resistant human cancer cells has not previously been examined. By observing single NK cells before and after contact with an NK-resistant target, we found significant granule clustering, but not polarization toward the IS. In fact, the movement of clustered granules away from the IS with MDA-MB-453 was seen in some cases. After CAR retargeting we observed an increased clustering degree, with effective completion of the whole cytotoxic process and killing of originally resistant cancer cells. We hypothesize that the stronger granule clustering was due to stronger activation signals provided by the CAR. It was previously reported that the NK cell line KHYG-1 has constitutively converged granules, without continuous degranulation. ${ }^{40}$ However, we found no evidence of permanently clustered granules in NK-92/5.28.z or haNK cells. Rather, our data suggest that granule clustering is a dynamic process where the degree of clustering depends on the strength of the activation signal. This is in agreement with prior data showing that highly IgG-coated S2 cells contribute to lytic granule convergence, while weak FcR-mediated signals are insufficient. ${ }^{41}$ Increased granule convergence was also observed in another study where primary NK cells and YTS cells were stimulated by IL-2. ${ }^{42}$ Overall, available evidence suggests that cell-cell contact (eg, LFA-1/ICAM-1) and/or cytokine signaling can lead to NK cell preactivation without lytic granule polarization and subsequent killing. ${ }^{20}$ It would be reasonable to assume that weak signals can preactivate NK cells through granule clustering, while awaiting a stronger signal that will lead to granule polarization and target killing.

Here we showed that CAR- or $\mathrm{mAb} / \mathrm{FcR}$-mediated signaling is able to induce granule polarization toward the IS with otherwise resistant breast cancer cells, while despite contact formation, polarization is not seen in non-retargeted NK cells. Previous reports showed that FcR-expressing NK-92 cells require in addition LFA-1 signaling for sufficient degranulation. ${ }^{21}$ This signal can be provided by ICAM-1 ligand expressed on MDA-MB-453 cells, leading to efficient cytotoxicity toward these targets. Since multiple receptors and activating pathways can be involved in clustering, polarization and degranulation, it remains unclear at present which pathway may be defective in the encounter of parental NK-92 and MDA-MB-453 cells. However, CAR- and or mAb/FcR-mediated interaction enables effective polarization, demonstrating that signaling through the ectopically expressed receptors can bypass the putative defective pathway or over-ride potential inhibitory signaling.

PI3K was shown previously to be activated in natural killing. ${ }^{43}$ Interestingly, we observed comparable activation of the PI3K pathway in NK-92 cells triggered by both resistant and sensitive targets. This suggest that PI3K activation contributes to granule clustering, but by itself may be insufficient to induce granule polarization. Accordingly, in unmodified NK-92 in contact with sensitive K562 cells, in addition to PI3K also activation of PLC $\gamma$ and MEK/ ERK pathways was found, which was not the case when encountering resistant MDA-MD-453 cells. In contrast, during CAR- and ADCC-mediated killing of MDA-MB-453 cells, PI3K, PLC $\gamma$ and MEK/ERK signaling pathways were again readily activated.

PLC $\gamma$ and MEK/ERK were reported to be stimulated by activating NK cell receptors such as NKG2D, and MEK/ ERK further triggered NK cell polarization and cytotoxicity. ${ }^{20}{ }^{44}$ Hence, the lack of polarization in parental NK-92 on contact with resistant MDA-MB-453 may be attributed to insufficient signaling through activating NK cell receptors, but which can be readily substituted by CAR and/ or ADCC.

Moreover, CAR NK-92 and haNK cells were recently shown to be insenstitive to hypoxic conditions, ${ }^{30} 45$ which is in contrast to NK cells from healthy donors. Whether polarization is blocked during hypoxia and what the activation signals are required for efficient cytotoxicity under hypoxic conditions, are clinically relevant questions which remain to be addressed.

To our knowledge, the comparative kinetics of natural cytotoxicity, CAR-NK-mediated cytotoxictiy and ADCC have not previously been studied in detail. Continuous LCI allowed us to measure the duration of the NK cell activation stages leading to tumor killing. The killing process was faster in CAR-retargeted NK cells compared with natural killing or ADCC, which might reflect differences in the nature of the receptors involved, or the receptor density on the cell surface. Detailed analysis of steps in the killing process revealed rapid polarization in both CAR NK cells and ADCC, while the steps between polarization and killing were more prolonged in ADCC than in CAR-retargeted NK cells, taking over $80 \%$ of the time period for the complete killing process compared with only $50 \%$ in the case of CAR NK cells. Recent work using high-resolution imaging and the degranulation indicator lysosomal-associated membrane protein 1 (LAMP-1)-pHluorin showed that pervasive actin remodeling is required for efficient degranulation, and the number and speed of the degranulation events correlate with the efficiency of natural cytotoxicity. ${ }^{12}{ }^{13}$ Whether the observed differences between CAR triggering and ADCC in postpolarizaion steps can be caused by different pervasiveness of actin networks due to different activation signals remains to be clarified.

Both CAR NK cells and haNK + Herceptin required in average only $\sim 1-2$ contacts between NK and cancer cell to kill the target, which is consistent with recently published single cell microfluidics analysis of CAR NK cells. ${ }^{46}$ Furthermore, we observed several instances of serial killing events. During those, an NK cell polarized to the first tumor cell and killed it, then repolarized toward a second target and killed it while still attached to the first one. It remains to be clarified how polarization of NK cell granules is regulated when there are two conjugation sites. 
The last step of natural cytotoxicity is described as IS termination. Our data suggest that IS termination is limited in retargeted NK cells. Termination was not executed by detachment of the receptors, but rather by tearing off part of the target cell membrane. Notably, our ADCC model includes high-affinity FcR that may also contribute to stronger binding compared with low affinity FcR. Therefore, we propose that CAR- or mAb-retargeted NK cells have limited ability to detach from target cells but can execute serial killing if another cancer cell comes in proximity of the original NK-target conjugate, or after the initial target cell is completely destroyed. In many solid tumors, the target cells are in close proximity to each other. Therefore, the ability of retargeted NK cells to remain bound to the tumor while killing additional cancer cells might increase the efficiency of these cytotoxic cells in solid tumors.

\section{CONCLUSION}

Overall, we conclude that granule polarization, but not granule clustering or cell conjugation, is the critical step leading to the failure of NK cell cytotoxicity in the resistant MDA-MB-453 breast cancer cell model. We showed that NK cell retargeting by CAR or mAbs (ADCC) can readily restore polarization against such initially resistant targets, and lead to efficient cytotoxicity, involving activation of PLC $\gamma$ and MEK/ERK pathways in addition to PI3K. For subsequent studies, it would be interesting to also investigate various other resistant cancer cell models to generate a more comprehensive view on the contributions of specific NK-cancer cell interactions, which may guide the development of further enhanced NK cell therapies.

\section{Author affiliations \\ ${ }^{1}$ Experimental Transfusion Medicine, Faculty of Medicine Carl Gustav Carus, Dresden University of Technology, Dresden, Germany \\ ${ }^{2}$ Institute for Transfusion Medicine, German Red Cross Blood Donation Service North-East, Dresden, Germany \\ ${ }^{3}$ Nantkwest Inc, Culver City, California, USA \\ ${ }^{4}$ Institute for Tumor Biology and Experimental Therapy, Georg-Speyer-Haus, Frankfurt am Main, Germany \\ ${ }^{5}$ Frankfurt Cancer Institute, Goethe University Frankfurt, Frankfurt am Main, Germany \\ ${ }^{6}$ German Cancer Consortium (DKTK), Partner Site Frankfurt/Mainz, Frankfurt am Main, Germany \\ ${ }^{7}$ German Cancer Consortium (DKTK), Partner Site Dresden, Dresden, Germany}

Correction notice This article has been corrected since it first published. The provenance and peer review statement has been included.

Acknowledgements The authors would like to thank Silke Tulok, Anja Nobst and Michael Gerlach for excellent light microscopy facility support; Maxmilian Kießler for his help with image analysis; Erik Zenker, Madeleine Teichert and Nicole Kronstein for outstanding technical assistance; Thomas Müller-Reichert, Marc Schmitz, Ben Wielockx, Jan Peychl, Romy Kronstein-Wiedemann and Julia Riewaldt for helpful discussion.

Contributors Designing of research studies: JE, NW and TT. Conducting experiments: JE, NW and NM. Acquiring data: JE and NW. Analyzing data: JE and NW. Writing the manuscript: JE, NW, LB, HGK, WW and TT. All authors read and approved the final manuscript.
Funding This research was supported in part by an Else-Kröner-Promotionskolleg fellowship to NW.

Competing interests TT and WW are named as inventors on patents in the field of cancer immunotherapy owned by their respective institutions. HGK and LB are employed by NantKwest, California, USA.

Patient consent for publication Not required.

Provenance and peer review Not commissioned; externally peer reviewed.

Data availability statement All data relevant to the study are included in the article or uploaded as online supplemental information.

Supplemental material This content has been supplied by the author(s). It has not been vetted by BMJ Publishing Group Limited (BMJ) and may not have been peer-reviewed. Any opinions or recommendations discussed are solely those of the author(s) and are not endorsed by BMJ. BMJ disclaims all liability and responsibility arising from any reliance placed on the content. Where the content includes any translated material, BMJ does not warrant the accuracy and reliability of the translations (including but not limited to local regulations, clinical guidelines, terminology, drug names and drug dosages), and is not responsible for any error and/or omissions arising from translation and adaptation or otherwise.

Open access This is an open access article distributed in accordance with the Creative Commons Attribution Non Commercial (CC BY-NC 4.0) license, which permits others to distribute, remix, adapt, build upon this work non-commercially, and license their derivative works on different terms, provided the original work is properly cited, appropriate credit is given, any changes made indicated, and the use is non-commercial. See http://creativecommons.org/licenses/by-nc/4.0/.

\section{ORCID iD}

Torsten Tonn http://orcid.org/0000-0001-9580-2193

\section{REFERENCES}

1 Long EO, Kim HS, Liu D, et al. Controlling natural killer cell responses: integration of signals for activation and inhibition. Annu Rev Immunol 2013;31:227-58.

2 Watzl C, Long EO. Signal transduction during activation and inhibition of natural killer cells. Curr Protoc Immunol 2010.

3 Liu E, Marin D, Banerjee P, et al. Use of CAR-Transduced natural killer cells in CD19-Positive lymphoid tumors. N Engl J Med 2020;382:545-53.

4 Tonn T, Becker S, Esser R, et al. Cellular immunotherapy of malignancies using the clonal natural killer cell line NK-92. J Hematother Stem Cell Res 2001;10:535-44.

5 Tonn T, Schwabe D, Klingemann HG, et al. Treatment of patients with advanced cancer with the natural killer cell line NK-92. Cytotherapy 2013;15:1563-70.

6 Björklund AT, Carlsten M, Sohlberg E, et al. Complete remission with reduction of high-risk clones following haploidentical NK-cell therapy against MDS and AML. Clin Cancer Res 2018;24:1834-44.

7 Zhu H, Lai Y-S, Li Y, et al. Concise review: human pluripotent stem cells to produce cell-based cancer immunotherapy. Stem Cells 2018;36:134-45.

8 Zhang C, Oberoi P, Oelsner S, et al. Chimeric antigen ReceptorEngineered NK-92 cells: an off-the-shelf cellular therapeutic for targeted elimination of cancer cells and induction of protective antitumor immunity. Front Immunol 2017;8:533.

9 Mehta RS, Rezvani K. Chimeric antigen receptor expressing natural killer cells for the immunotherapy of cancer. Front Immunol 2018;9:283.

10 Klingemann $\mathrm{H}$, Boissel L, Toneguzzo F. Natural killer cells for immunotherapy - advantages of the NK-92 cell line over blood NK cells. Front Immunol 2016;7:91.

11 Jochems C, Hodge JW, Fantini M, et al. An NK cell line (haNK) expressing high levels of granzyme and engineered to express the high affinity CD16 allele. Oncotarget 2016;7:86359-73.

12 Rak GD, Mace EM, Banerjee PP, et al. Natural killer cell lytic granule secretion occurs through a pervasive actin network at the immune synapse. PLoS Biol 2011;9:e1001151.

13 Gwalani LA, Orange JS. Single Degranulations in NK cells can mediate target cell killing. J Immunol 2018;200:3231-43.

14 Mentlik AN, Sanborn KB, Holzbaur EL, et al. Rapid lytic granule convergence to the MTOC in natural killer cells is dependent on dynein but not cytolytic commitment. Mol Biol Cell 2010;21:2241-56.

15 Hsu H-T, Orange JS. Distinct integrin-dependent signals define requirements for lytic granule convergence and polarization in natural killer cells. Sci Signal 2014;7:pe24. 
16 Mace EM, Dongre P, Hsu H-T, et al. Cell biological steps and checkpoints in accessing NK cell cytotoxicity. Immunol Cell Biol 2014;92:245-55.

17 Barber DF, Faure M, Long EO. Lfa-1 contributes an early signal for NK cell cytotoxicity. J Immunol 2004;173:3653-9.

18 Bryceson YT, March ME, Barber DF, et al. Cytolytic granule polarization and degranulation controlled by different receptors in resting NK cells. J Exp Med 2005;202:1001-12.

19 Tuli A, Thiery J, James AM, et al. Arf-Like GTPase Arl8b regulates lytic granule polarization and natural killer cell-mediated cytotoxicity. Mol Biol Cell 2013;24:3721-35.

20 Chen X, Trivedi PP, Ge B, et al. Many NK cell receptors activate ERK2 and JNK1 to trigger microtubule organizing center and granule polarization and cytotoxicity. Proc Natl Acad Sci U S A 2007;104:6329-34.

$21 \mathrm{Hsu} \mathrm{H}-\mathrm{T}$, Mace EM, Carisey AF, et al. Nk cells converge lytic granules to promote cytotoxicity and prevent bystander killing. J Cell Biol 2016;215:875-89.

22 Aldeghaither DS, Zahavi DJ, Murray JC, et al. A mechanism of resistance to antibody-targeted immune attack. Cancer Immunol Res 2019;7:230-43.

23 Romanski A, Bug G, Becker S, et al. Mechanisms of resistance to natural killer cell-mediated cytotoxicity in acute lymphoblastic leukemia. Exp Hematol 2005;33:344-52.

24 Maki G, Hayes GM, Naji A, et al. Nk resistance of tumor cells from multiple myeloma and chronic lymphocytic leukemia patients: implication of HLA-G. Leukemia 2008;22:998-1006.

25 Hasenkamp J, Borgerding A, Wulf G, et al. Resistance against natural killer cell cytotoxicity: analysis of mechanisms. Scand J Immunol 2006;64:444-9.

26 André P, Denis C, Soulas C, et al. Anti-NKG2A mAb is a checkpoint inhibitor that promotes anti-tumor immunity by Unleashing both $\mathrm{T}$ and NK cells. Cell 2018;175:e13:1731-43.

27 van Hall T, André $P$, Horowitz A, et al. Monalizumab: inhibiting the novel immune checkpoint NKG2A. J Immunother Cancer 2019;7:263.

28 Schönfeld K, Sahm C, Zhang C, et al. Selective inhibition of tumor growth by clonal NK cells expressing an ErbB2/HER2-specific chimeric antigen receptor. Molecular Therapy 2015;23:330-8.

29 Maki G, Klingemann HG, Martinson JA, et al. Factors regulating the cytotoxic activity of the human natural killer cell line, NK-92. J Hematother Stem Cell Res 2001;10:369-83.

30 Zhang C, Burger MC, Jennewein L, et al. ErbB2/HER2-Specific NK cells for targeted therapy of glioblastoma. J Natl Cancer Inst 2016;108. doi:10.1093/jnci/djv375. [Epub ahead of print: 0612 2015].

31 Uherek C, Tonn T, Uherek B, et al. Retargeting of natural killer-cell cytolytic activity to ErbB2-expressing cancer cells results in efficient and selective tumor cell destruction. Blood 2002;100:1265-73.
32 Mukherjee M, Mace EM, Carisey AF, et al. Quantitative imaging approaches to study the CAR immunological synapse. Mol Ther 2017;25:1757-68.

33 Burger MC, Zhang C, Harter PN, et al. CAR-Engineered NK cells for the treatment of glioblastoma: turning innate effectors into precision tools for cancer immunotherapy. Front Immunol 2019;10:2683.

34 Liu E, Tong Y, Dotti G, et al. Cord blood NK cells engineered to express IL-15 and a CD19-targeted CAR show long-term persistence and potent antitumor activity. Leukemia 2018;32:520-31.

35 Nowakowska P, Romanski A, Miller N, et al. Clinical grade manufacturing of genetically modified, CAR-expressing NK-92 cells for the treatment of ErbB2-positive malignancies. Cancer Immunol Immunother 2018;67:25-38.

36 Romanski A, Uherek C, Bug G, et al. CD19-CAR engineered NK92 cells are sufficient to overcome NK cell resistance in B-cell malignancies. J Cell Mol Med 2016;20:1287-94.

37 Huang Y, Chen Z, Jang JH, et al. Pd-1 blocks lytic granule polarization with concomitant impairment of integrin outside-in signaling in the natural killer cell immunological synapse. J Allergy Clin Immunol 2018;142:1311-21.

38 Burshtyn DN, Shin J, Stebbins C, et al. Adhesion to target cells is disrupted by the killer cell inhibitory receptor. Current Biology 2000;10:777-80.

39 Urlaub D, Höfer K, Müller M-L, et al. Lfa-1 activation in NK cells and their subsets: influence of receptors, maturation, and cytokine stimulation. J Immunol 2017;198:1944-51.

40 Suck G, Branch DR, Aravena P. Constitutively polarized granules prime KHYG-1 NK cells. Int Immunol 2006;18:1347-54.

41 Zhang M, March ME, Lane WS, et al. A signaling network stimulated by 2 integrin promotes the polarization of lytic granules in cytotoxic cells. Sci Signal 2014;7:ra96.

42 James AM, Hsu H-T, Dongre P, et al. Rapid activation receptoror IL-2-induced lytic granule convergence in human natural killer cells requires Src, but not downstream signaling. Blood 2013;121:2627-37

43 Jiang K, Zhong B, Gilvary DL, et al. Pivotal role of phosphoinositide-3 kinase in regulation of cytotoxicity in natural killer cells. Nat Immunol 2000;1:419-25

44 Upshaw JL, Schoon RA, Dick CJ, et al. The isoforms of phospholipase C-gamma are differentially used by distinct human NK activating receptors. J Immunol 2005;175:213-8.

45 Solocinski K, Padget MR, Fabian KP, et al. Overcoming hypoxiainduced functional suppression of NK cells. J Immunother Cancer 2020;8:e000246.

46 Ravi D, Sarkar S, Purvey S, et al. Interaction kinetics with transcriptomic and secretory responses of CD19-CAR natural killercell therapy in CD20 resistant non-Hodgkin lymphoma. Leukemia 2020;34:1291-304. 
Correction: Inability of granule polarization by NK cells defines tumor resistance and can be overcome by CAR or ADCC mediated targeting

Eitler J, Wotschel N, Miller N, et al. Inability of granule polarization by NK cells defines tumor resistance and can be overcome by CAR or ADCC mediated targeting. $J$ Immunother Cancer 2021;9:e001334. doi:10.1136/jitc-2020-001334

This article has been corrected since it first published. The provenance and peer review statement has been added.

Open access This is an open access article distributed in accordance with the Creative Commons Attribution Non Commercial (CC BY-NC 4.0) license, which permits others to distribute, remix, adapt, build upon this work non-commercially, and license their derivative works on different terms, provided the original work is properly cited, appropriate credit is given, any changes made indicated, and the use is non-commercial. See http://creativecommons.org/licenses/by-nc/4.0/.

(C) Author(s) (or their employer(s)) 2021. Re-use permitted under CC BY-NC. No commercial re-use. See rights and permissions. Published by BMJ.

J Immunother Cancer 2021;9:e001334corr1 . doi:10.1136/jitc-2020-001334corr1

A) Check for updates 